"Regulation as a policy contest: the probability of conservation of a renewable resource"

\begin{tabular}{ll} 
AUTHORS & Urs Steiner Brandt \\
\hline ARTICLE INFO & $\begin{array}{l}\text { Urs Steiner Brandt (2017). Regulation as a policy contest: the probability of } \\
\text { conservation of a renewable resource. Environmental Economics, 8(3), 92-101. } \\
\text { doi:10.21511/ee.08(3-1).2017.01 }\end{array}$ \\
\hline DOI & http://dx.doi.org/10.21511/ee.08(3-1).2017.01 \\
\hline RELEASED ON & Wednesday, 11 October 2017 \\
\hline RECEIVED ON & Saturday, 15 July 2017 \\
\hline ACCEPTED ON & Tuesday, 22 August 2017 \\
\hline LICENSE & $\begin{array}{l}(c) \text { Er-Ne } \\
\text { This work is licensed under a Creative Commons Attribution-NonCommercial } 4.0\end{array}$ \\
\hline JOURNAL & International License \\
\hline ISSN PRINT & "Environmental Economics" \\
\hline ISSN ONLINE & $1998-6041$ \\
\hline PUBLISHER & $1998-605 X$ \\
\hline FOUNDER & LLC “Consulting Publishing Company "Business Perspectives" \\
\hline
\end{tabular}

NUMBER OF REFERENCES

24

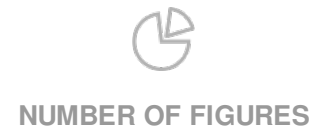

5
NUMBER OF TABLES

0

(C) The author(s) 2022. This publication is an open access article. 
Urs Steiner Brandt (Denmark)

\title{
Regulation as a policy contest: the probability of conservation of a renewable resource
}

\begin{abstract}
How do the levels of extreme positions of various interest groups influence the conservation policies in the context of a renewable resource conservation contest? To answer this question, a model is provided where conservation policy is determined as a contest between two opposing interest groups: one in favor of conservation and another in favor of non-conservation. The levels of extreme positions for the conservationalists are determined by their demands about the severity of the conservation strategy that needs to be implemented. For the non-conservation group, the level of extreme position is determined by how large the current harvest of the resource should be.

The main driver of the model is that resource conservation is realized only if the conservation group wins the contest, which again depends on the relative gain the two contenders receive when winning the contest. The paper derives conditions where the more extreme positioned groups will have less likelihood of succeeding, e.g., a conservation group demanding larger conservation efforts will face a reduced probability that actual conservation policies will be implemented.
\end{abstract}

Keywords: political contest, probability of conservation, resource management, environmental degradation, extreme positions.

JEL Classification: Q22, D72, L5.

Received on: $13^{\text {th }}$ of July, 2017.

Accepted on: $22^{\text {nd }}$ of August, 2017.

\section{Introduction}

In recent years, the idea that natural resources (e.g., the seas of Europe) should be brought back to a state of "good environmental (or ecological) status" has influenced regulation ${ }^{1}$. However, conservation will likely happen at the expense of the (short run) interests of the harvester of the resource. At times, the conservation groups even argued for a full stop of harvest for a number of years, e.g., WWF (2006).

Harvesters of the resource who are concerned about the short-run profitability will have incentives to try to affect policy by lobbying against cut-backs in the allowable harvest ${ }^{2}$.

Against this background, the forthcoming politically determined harvest level is modelled as a political contest between the harvesters, on the one hand, and the conservationalists, on the other hand.

(c) Urs Steiner Brandt, 2017.

Urs Steiner Brandt, Ph.D., Associate Professor, Department of Sociology, Environmental and Business Economics, University of Southern Denmark, Campus Esbjerg, Denmark.

This is an Open Access article, distributed under the terms of the Creative Commons Attribution-NonCommercial 4.0 International license, which permits re-use, distribution, and reproduction, provided the materials aren't used for commercial purposes and the original work is properly cited.

${ }^{1}$ As an example, the Marine Strategy Framework Directive (MSFD) came into force in 2008. Essentially the target is to reach good environmental status (GEnS) in 2020 in all EU member states (EU, 2005; Juda, 2010; Long, 2011).

${ }^{2}$ See Brandt and Svendsen (2016) for an overview over lobby activity in the EU and its economic, social and environmental consequence. For a more general presentation of political economy applied to environmental issues see Hovi et al. (2011).
The harvesters opt for a larger harvest, the conservation group, interested in establishing good environmental/ecological status, opt for a larger stock by demanding a smaller current harvest. Without any lobbying, the policy makers will make a balanced policy. In this type of model, the probability that a specific outcome will be chosen depends on the relative gains the two groups receive from winning the contest.

Both groups can be more or less extreme regarding their demands. The conservation group is called more extreme if it demands a larger stock and, hence, less harvests, while the harvest group is more extreme when demanding larger harvest resulting in a lower future stock.

The research questions of this paper are as follows: under what conditions will a more extreme positioned conservation group will make it more likely that the resource will actually be protected. Furthermore, if the resource is under pressure due to worsened environmental conditions, how will this affect the probability that the resource is conserved? And how does this relate to the extreme position of the interest groups? And finally it also addresses the question of how the probability of conservation is affected when the political agenda shift in favor of one group.

Political contest models have been applied to analyze contests between competing interest groups (Nitzan, 1994), coordination efforts by interest 
groups sharing the same objective of influencing the provision of a specific public good (Dijkstra, 1998), and the interaction between an interest group and a two-tier government in which the interest group tries to influence politicians to reject or accept proposals made by agenda-setting bureaucrats (Epstein $\&$ Nitzan, 2002). The specification of the model in the current paper resembles that of Epstein and Nitzan (2002), in which two interest groups compete over the provision of a public good that is beneficial to one group and costly to the other group.

Several papers use the same type of political contest model as the current paper's model in an environmental and conservation context. In Graichen et al. (2001), a political contest is modelled between a local environmental group and a monopoly over a local energy system. As in our model, the probability of winning the contest depends on the relative gain (utility vs. profit) from winning the contest. One finding of their analysis is that when the monopoly is threatened by an environmental pressure group, then it is optimal for the monopoly to reduce emission, thereby increasing the probability of wining the implicit contest. Also Liston-Heyes (2001) analyzes a contest between a developer wishing to undertake a project and an environmental group that opposes planning consent. Liston-Heyes (2001) makes policy proposals endogenous in the sense that the contenders take into account that their proposals also affect the preferred position of the other contenders. Their result is that treating the policy proposals endogenously implies less aggressive action from the contesters. The current paper does treat the proposals of the contender exogenous, but instead considers how policy is affected by the various positions that the contender could hold.

The current paper assumes a unified decision makers and that there exists full information. Two papers have analyzed the contest model where these assumptions are challenged. Epstein et al. (2007) and Epstein et al. (2008) include incomplete information in the contest model, where the contesters do not know where the centre of powers lays leading to less distortion in the political process. Also a two-sided contest is considered by Epstein et al. (2008), where the contenders both use lobby effort not only in the ordinary policy contest, but also in a contest about supporting the various source of power (bureaucrats and/or politicians).

This current paper adds to another feature too this stand of the literature by considering how the probability of winning the context depends on "extreme" position of the two contending groups. It also adds to the analysis of how changes in environmental conditions affect these results. The paper that comes closest to this papers analysis is the paper by Eerola (2004) who analyzes a lobby contest about forest conservation between an environmental lobby group and a lobby group representing an industrial wood producer. Here the policy outcome is forest conservation, and the relatively most efficient lobby group has the largest probability of winning the contest. Instead of efficiency in lobbying, in our model, the relative gain from winning the contest determines the probability of winning the contest ${ }^{3}$.

A novelty of the analysis of this paper is how the two groups preferred policy outcome affects the probability of conservation. The point of departure with respect to the behavior of the harvesters is the assumption that the harvesters are organized in one lobby group with the objective of maximizing a weighted sum of current profit and total intertemporal profit for the group as a whole. Such a preferred policy proposal of the harvesters is too high compared to one that maximizes the intertemporal profit ${ }^{4}$. A question that naturally arises here is why the harvester's organization prefers a policy that does not fully directly maximize intertemporal profit. One obvious reason is that the harvester's organization does not have sufficient discretion over the individual harvester. A well-established fact in the literature on fisheries is that individual fisheries are either in a common pool or an open access situation, both of which give the individual fishermen incentive to maximize their short run profit, which again implies that they will not consider the future profitability of the industry ${ }^{5}$. Olson (1965) states that the

\footnotetext{
3 In some case, there might be an alignment between harvester and conservation issues and then no real contest emerges. In Brandt and Svendsen (2009), this result emerges when the fishermen receive high subsidies when performing bad and incentives exists that interests between fishermen and environmentalists are aligned.

${ }^{4}$ It should be noted that many papers find that regulation is not effective in achieving sustainable harvesting levels, in particular in fisheries. According to Pitcher (2001), the ecosystem is constantly eroded, partly due to the fact that fishing efforts act as a selection mechanism favoring short lived, fast growing fish (Pauly, 1995) and partly due to a series of political and economic imperatives that drives the system in a downward spiral (Ludwig et al., 1993). The main lesson from these observations is that that there is an inherent incentive structure which implies overfishing regardless of regulation, aside from a total closure of the industry.

${ }^{5}$ Wilen (2000) nicely describes the development of economic theory into fishery regulations, pointing out that the most promising approaches recently have been the introduction of individually transferable quotas (ITQs). Although ITQs can solve many of the problems in fisheries with respect to overcapitalization (problems such as insufficient effort per boat and too many harvesters) and therefore tend to increase the profitability of the industry, it will not necessarily in itself solve the problem of overfishing resulting from political pressure to set the number of issued quotas too high, although higher quotas implies lower quota prices.
} 
commonality of the goals of an interest group's members makes the achievement of these goals a public good for the group, which thus gives rise to the same incentives to free-riding in all public good and prisoners' dilemma situations ${ }^{6}$.

The second group that has the power to influence the decision of how to manage the renewable resource is an environmental group with the aim of conservation of the resource ${ }^{7}$. More specifically, its agenda is to increase the stock size of the resource to an "acceptable" level. When the conservationists win the contest, the adopted policy is one of conserving the resource. We vary the objective of the environmentalists groups from choosing a policy that secures maximum sustainable yield (MSY, which is the weakest requirement) to preferring a stock close to its natural equilibrium (implying very small or none harvesting pressure).

The more extreme positions of the environmentalists can be motivated by a desire of safeguarding the stocks in case of unforeseen (stochastic) temporary shocks that could force the stock below its minimum level with long lasting adverse consequences ${ }^{8}$. The objective of these types of conservationalists is, therefore, to secure the stock of the renewable resource by temporarily closing the harvesting activity ${ }^{9}$.

The result of the contest depends on the relative gain that the two interest groups receive from winning the contest (compared to loosing). When, for example, the net gain for the harvesters from winning increases (while it remains constant for the

\footnotetext{
${ }^{6}$ Two important conclusions can be drawn from this observation: (1) it is easier to form an interest group when the number of potential members is smaller than when the number is larger; and (2) thus, the establishment of an organization that effectively represents large numbers of individuals requires that "separate and 'selective' incentives" be used to curb free-riding behavior.

${ }^{7}$ We treat the conservation group as one monolith group. In reality the conservation and environmental side is covered by many special interest groups and/or NGOs. Richards and Heard (2005) give a description of various NGOs involved in the implementation process of the EU marine policy.

${ }^{8}$ As an example of the objectives of the conservationalists in a fisheries context: the International Council for the Exploration of the Sea (ICES) has been calling for a complete ban on cod fishing in the North Sea, Irish Sea and west of Scotland, in order to prevent cod stocks from going the way of the Canadian cod stocks which collapsed in the early 1990s, see ICES (2005).

${ }^{9}$ Brandt and Svendsen (2009) analyze this in a strategic context: if the regulator is uncertain of the true stock, then situations exist in which conservationalists prefer overfishing in the short run, since with declining stocks (and eventually declining catches) the biologists might find it easier to convince the regulator to stop the fisheries. This scheme works best in the presence of subsidies.
}

conservationalists), then the harvesters will invest more in winning the contest, and as a consequence, the probability that they will win increases. This result is then linked to the positions that the two groups hold. The general result here is that if a group hold a more extreme position, the probability that the resource will be conserved will increase only if the that group receives a larger percentage increase in the net benefit from winning the contest than does the opposing group.

This paper also analyzes how changed environmental conditions influence the relative benefits for the two competing interest groups through its effect on biological background variables, and consequently, how the probability of conservation is linked to such changes ${ }^{10}$. Changed environmental conditions are likely to affect the two interest groups' gain differently. One striking result is that when environmental conditions worsen, this negatively affects the probability that the resource is conserved, under the condition that the percentage net benefit from winning increases more for the harvesters than for the conservationalists.

The paper is organized as follows: the next section analyzes the behavior of the harvesters and the conservationalists and the possible development in stock and harvest, while section 2 states the political contest model. Given this set-up, section 3 provides the analysis of how various factors of the model influences the probability of conservation. In particular, the effect of the relative position of the group on policy output, and effect of worsening of environmental conditions and cost asymmetries.

\section{The harvesting/conservation model}

Let us consider a renewable resource that is harvested. The stock is denoted $S$ and the harvest $h$. The exact harvest level is politically determined. Without any lobbying, the harvest level is determined by scientific parameters like development in stock, technology, etc. However, in this paper, the political contest model is taken to its extreme, in that the winners' preferred outcome will be fully implemented. Therefore, the chosen harvest level is fully affected by lobbying effort by two opposing lobby groups: group representing the

\footnotetext{
${ }^{10}$ The paper also addresses the analyses of the effects of changed environmental conditions on the policy outcome. One major possibility of such changed environmental conditions is climate change. The fifth report of the Intergovernmental Panel on Climate Change (IPCC, 2014) estimates an increase in the global mean temperature in the range of 0.34.8 degrees by end of the century. This is very likely to affect the future profitability of most renewable resources, like fisheries and forestry. With respect to fisheries, climate change is expected to influence the recruitment, size and quality of the fish resource, changes in migration of species, or even changes in transportation of larvae. See, e.g., Buck et al. (2004).
} 
harvesters and a group representing the conservationalists. Two groups enter a political contest to determine the harvest/stock size of the renewable resource. Each group has a preferred position/policy proposal. The harvesters interested in a preferred harvest level and the conservationalists are interested in a preferred stock size.

First, we set-up the basic model by considering the optimal policies for the two groups and thereafter a political contest is applied to determine the expected outcome of this political process.

The model uses the following assumptions ${ }^{11}$ :

A1: The chosen policy will prevail.

A2: The agreed upon harvest rule is a rule that specifies a path that the harvest must take over time.

A3: If the conservation group wins the contest, $S$ increases and $h$ decreases in the periods to come and if the harvesting group wins the contest $h$ increases and $S$ decreases over time.

A4: Each group has its preferred harvest level (e.g., harvest level per year).

Regarding A1, once the policy is chosen, no further possibilities for influencing the harvest are given by any parties. We can justify this considering the policy as being a determination of a long-run trend.

A2 defines an implicit dynamics that is not explicitly modelled. $h$ is the harvesting rule to follow over a non-specified period of time. By $S$ we denote the resulting stock given the chosen policy. As with the harvest, $S$ can be interpreted as a path that the stock will follow over the same time span as the harvesting rule.

By A3 it is assumed that if the conservation group wins the contest, then the stock will increase and the harvest will decrease in the periods to come. The more demanding the conservation group regarding the requirement on the stock, the smaller will the harvest be ${ }^{12}$.

In a parallel fashion, if the harvesting group wins the contest, then the harvest will increase, and the stock will decrease in the periods to come. The more demanding the harvesting group regarding the requirement on the harvest, the smaller will the stock be over time. However, there is a possibility that a large temporary increase in harvest and

\footnotetext{
${ }^{11}$ These assumptions will be discussed further in the conclusion.

${ }^{12}$ We disregard the possibility of a large temporary reduction in harvest and thereby increase in stock over time might result in an increase of the harvest in later periods.
}

thereby decrease in stock over time could result in lower feasible harvests in later periods.

Once we have defined the position that the two contenders can hold, we show an example of the path that the stock and the harvest can follow. Assumption A4 is described in detail in the next section, where the preferred harvest level of the two groups is derived.

1.1. The harvesters' preferred outcome. Let us define $\boldsymbol{h}=\boldsymbol{h}^{\boldsymbol{M E Y}}$ as the harvest level that maximizes the intertemporal profit for the harvesting group. The resulting profit is denoted $\pi^{\mathbf{T}}$, being the maximum NPV of current and all future profit from harvesting (for a given discount rate). On the other extreme, we define open access as a situation where $\boldsymbol{\pi}^{\boldsymbol{O A}}=\boldsymbol{\pi}\left(\boldsymbol{h}^{\boldsymbol{O A}}, \boldsymbol{S}^{\boldsymbol{O A}}\right) \rightarrow \boldsymbol{0}$. In this situation, harvest levels are continuously so high that profits approach zero in the long run, but in comparison with $\mathbf{h}^{\mathbf{M E Y}}$, significantly higher profit in the short run. Open access implies lobbying for large harvest due to a high focus on short-run profit at the expense of future profits. We have that $\mathbf{h}^{\mathbf{O A}}>\mathbf{h}^{\mathbf{M E Y}}$, but over time $\boldsymbol{\pi}\left(\boldsymbol{h}^{\boldsymbol{O A}}\right)<\boldsymbol{\pi}\left(\boldsymbol{h}^{\mathbf{M E Y}}\right)$.

A well-established fact in the literature is that the individual harvester (e.g., individual fisherman) has an incentive to maximize his short-run profit and not to consider the future profitability of the industry. On the other hand, such behavior is not collectively rational for the harvester group as a whole. However, harvesters are often part of an organization that promotes the policies which serve the harvesters' interests, and such an organization faces the underlying problem of balancing between what is best for the group and best for the individual. To capture this incentive problem, we introduce a parameter $\alpha \in[0,1]$ measuring the level of the inability of the harvesters' organization to maximize the groups' profit. If $\alpha$ approaches 1 , then we are in a situation where the harvesters act in a fully open access context. The other extreme is a situation with a harvest organizations has full discretion over the actions of the harvester, or a sole owner (monopolist) operating in the industry, who would fully take into account how current harvesting affects future profitability implying an $\alpha$ approaches 0 .

The position of the group determines its preferred harvest level. $\alpha=1$ implies $h^{\mathrm{OA}}$ accomplished by a high current harvest level and a stock that over times is reduced, and profit reduced over time approaching $0 . \alpha=0$ implies $\mathrm{h}^{\mathrm{MEY}}$ accomplished by a moderate harvest level and a stock that, depending on the current size of the stock, can increase or decrease over time, but 
approaches a level well above open access, and where the profit over time approaches the highest possible defined by the maximum sustainable yield.

It is therefore possible to define the preferred harvest level, $h$, as a function of $\alpha$, and we write $h^{\alpha}$, with $\frac{d h^{\alpha}}{d \alpha}=h_{\alpha}^{\alpha}>0$. We define $\pi=\pi\left(h^{\alpha} ; \alpha\right)$ as the profit function for a group with $\alpha$, in the understanding that $\pi_{\alpha}>0$ for $h<h^{\alpha}$ and $\pi_{\alpha}<0$ for $h>h^{\alpha}{ }^{13}$. For a given position of the harvester, and resulting $h^{\alpha}$, a unique path of $\mathrm{S}$ will emerge, denoted by: $S^{\alpha}=$ $S\left(h^{\alpha}\right)$.

The larger $\alpha$, the less weight is put on future profit and therefore the larger a current harvest is opt for in the political contest with the conservationalists. Note that $\alpha$ can be interpreted as a measurement of the level of "extreme position" of the harvesting group, with $\alpha=1$ being the most extreme in terms of demands on current harvests.

1.2. The conservationalists' preferred outcome. Turning to the conservationalists, this group has solely preferences over the "development in the stock", and their target is a harvest policy that brings the stock as close as possible to what the group defines as being optimal $^{14}$.

The conservationalists might, however, vary by the preferred stock size. An extreme position will be to reestablish a natural equilibrium (denoted $S^{C C}$ for the stock size at the carrying capacity), amounting to zero or very limited harvest, while others would prefer a less extreme approach. The other extreme being a stock size of $S^{M S Y}<S^{C C}$, which implies a permanently high harvest and a considerable less stock size ${ }^{15}$.

To capture the whole range of possibilities, we assume that any conservationalist position resulting in stock between $S^{C C}$ and $S^{M S Y}$ is possible. Define $\beta \in(0,1)$ as a measure of the degree of extreme position, and define $S=$ $S(\beta)$, where $S(\beta=1)=S^{C C}$ and $S(\beta=0)=$ $S^{M S Y}$.

$S^{\beta}$ is the preferred stock for a given $\beta$, such that $S_{\beta}^{\beta}>0$. Formally, the $S^{\beta}$ is derived as follows. We assume that the conservationalists have single peaked preferences and these preferences are represented by a utility function:

$$
\begin{gathered}
u^{C}=u^{C}(S ; \beta) \\
u_{S}^{C}>0 \text { for } S<S^{\beta}, u_{S}^{C}=0 \\
\text { for } S=S^{\beta} \text { and } u_{S}^{C}<0 \text { for } S>S^{\beta} .
\end{gathered}
$$

Finally, the desired stock translates into a harvest policy. Each $S(\beta)$ results in one harvest rule, call $h^{\beta}=h\left(S^{\beta}\right)$. It follows that $h_{\beta}^{\beta}<0$. Given the way the relationship between harvest and stock is specified, it follows that a demand of a higher stock implies a lower harvest path. Figure 1 repeats the interpretation of $\alpha$ and $\beta$.

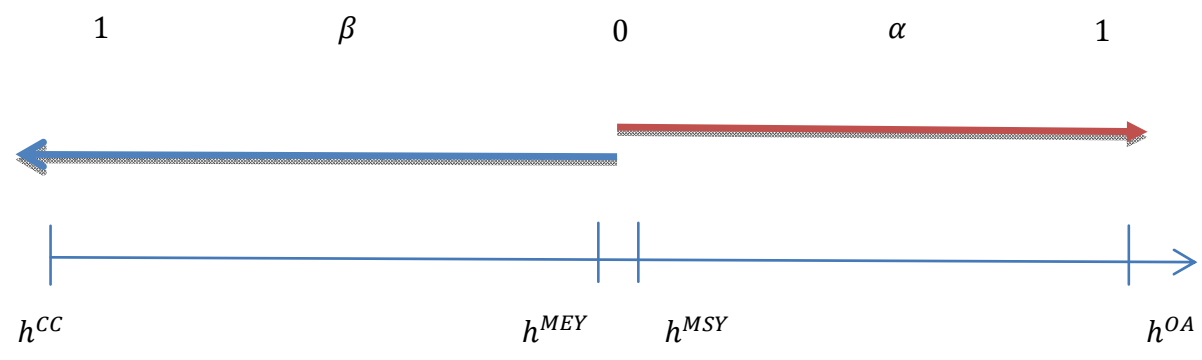

Fig. 1. The possible positions of the two competing groups

\footnotetext{
${ }^{13}$ Notationally, we sometimes use subscripts to denote derivate, like $\frac{d h^{\alpha}}{d \alpha}=h_{\alpha}^{\alpha}$ and likewise $\frac{d^{2} h^{\alpha}}{d \alpha d \alpha}=h_{\alpha \alpha}^{\alpha}$.

${ }^{14}$ E.g., how large a stock is required in a "good ecological /environmental status" case, e.g., as defined by prescriptors in EU GES (EU, 2008).

${ }^{15}$ We could have chosen other point here, but the $S^{M S Y}$, but choice of the two targets reflect two extreme position, one where conservationalists not care at all about the harvest opportunities and one where the steady state harvest is maximized.
} 
Finally, to give an impression of the dynamics and how the contenders' positions affect the path of the stock and the harvest, let us consider that the policy determined at time $t^{O}$ stretches out until time $t^{T}>0$.

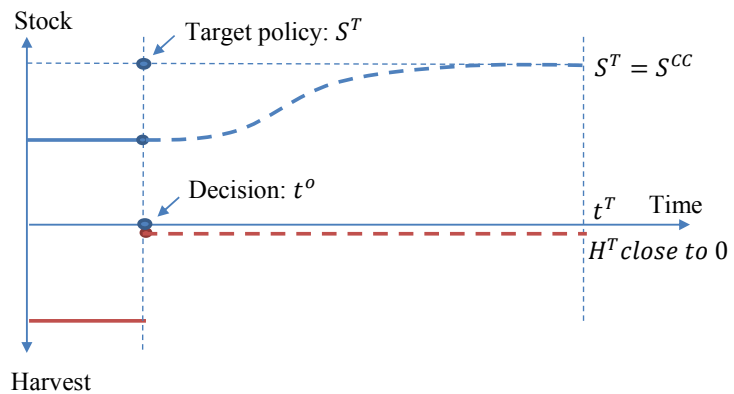

Fig. 2. Situation where $\beta=1$

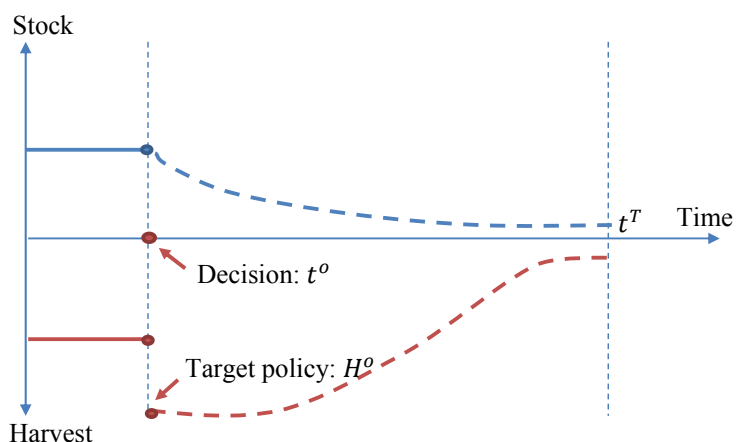

Fig. 4. Situation where $\alpha=1$

\section{The political contest}

In the political contest, the probability that the preferred policy of the conservation group is selected is $p^{C}$, while the probability of selection of the harvester's preferred policy is $p^{H}=1-p^{C}$.

In this type of political contest model, it is generally assumed that the contenders can affect the probabilities by their contribution levels. The existence of a contest success function (CSF) is also assumed which specifies the probability of approval of the proposed policy corresponding to the rent-seeking effort of the interest groups (see Epstein \& Nitzan, 2002). Let $x^{H}$ and $x^{C}$ be the contribution of the harvester's group and the conservationalists, respectively. A commonly used CSF is the constant returns to scale nondiscriminating rule: $p^{H}=x^{H} /\left(x^{H}+x^{C}\right)$ and $p^{C}=x^{C} /\left(x^{H}+x^{C}\right)$. The policy proposals of the two contenders are exogenous (but dependent on $\alpha$ and $\beta$, respectively), in the sense that the two groups choose their referred action without considering how their choice affects the other group's behaviour.

In order to set up the political contest, we introduce expected welfare functions of the two contenders:
The Figures 2-4 show possible paths for $S$ and $h$ for the most extreme position such that any intermediate position has a development in between the largest and lowest possible position ${ }^{16}$.

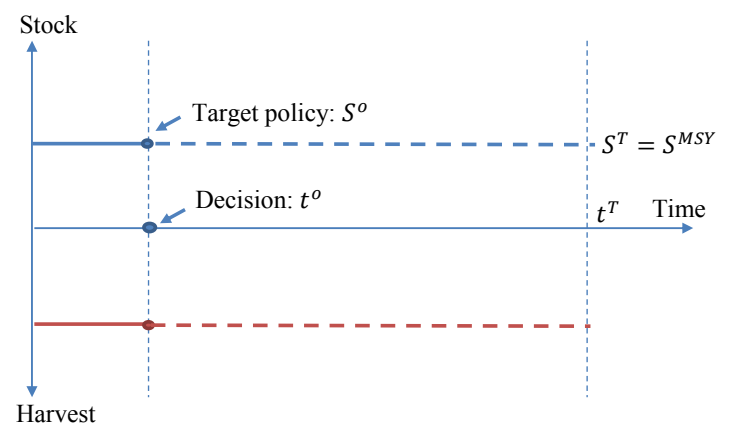

Fig. 3. Situation where $\boldsymbol{\beta}=\mathbf{0}$

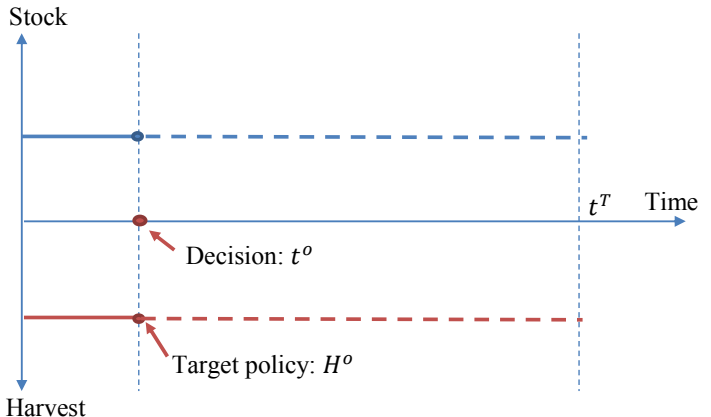

Fig. 5. Situation where $\alpha=0$

$$
\begin{aligned}
& E\left[W^{H}(\alpha, \beta)\right]=P^{H} \cdot \pi\left(h^{\alpha}, \alpha\right)+P^{C} \cdot \pi\left(h^{\beta}, \alpha\right)-x^{H} \\
& E\left[W^{C}(\alpha, \beta)\right]=P^{C} \cdot u\left(S^{\beta}, \beta\right)+P^{H} \cdot u\left(S^{\alpha}, \beta\right)-x^{C}
\end{aligned}
$$

Let the net benefit from winning the contest for the contenders be:

$$
\begin{aligned}
& N^{H}(\alpha, \beta)=\pi\left(h^{\alpha}, \alpha\right)-\pi\left(h^{\beta}, \alpha\right) \\
& N^{C}(\alpha, \beta)=u\left(S^{\beta}, \beta\right)-u\left(S^{\alpha}, \beta\right)
\end{aligned}
$$

The net benefit functions are determined by the difference in the welfare from winning and losing the contest. Therefore, any change that makes the welfare from losing smaller will increase the net benefit from wining the contest. Inserting these into back into the welfare functions yield:

$$
\begin{aligned}
& E\left[W^{H}(\alpha, \beta)\right]=P^{H} \cdot N^{H}(\alpha, \beta)+\pi\left(h^{\beta}, \alpha\right)-x^{H} \\
& E\left[W^{C}(\alpha, \beta)\right]=P^{C} \cdot N^{C}(\alpha, \beta)+u\left(S^{\alpha}, \beta\right)-x^{C}
\end{aligned}
$$

Solving for the contribution give the Nash equilibrium contribution levels:

$$
x^{H}=\frac{N^{C}\left(N^{H}\right)^{2}}{\left(N^{H}+N^{C}\right)^{2}} ; x^{C}=\frac{N^{H}\left(N^{C}\right)^{2}}{\left(N^{H}+N^{C}\right)^{2}}
$$

\footnotetext{
${ }^{16}$ In Figure 4, it is for simplicity assumed that $S^{M S Y}=S^{M E Y}$
} 
Inserting into $p^{C}=x^{C} /\left(x^{H}+x^{C}\right)$, yield the equilibrium probability of conservation solely as a function of the net benefits of winning the contest:

$$
\begin{gathered}
p^{H}(\alpha, \beta)=\frac{N^{H}(\alpha, \beta)}{N^{H}(\alpha, \beta)+N^{C}(\alpha, \beta)} \\
p^{C}(\alpha, \beta)=\frac{N^{C}(\alpha, \beta)}{N^{H}(\alpha, \beta)+N^{C}(\alpha, \beta)}
\end{gathered}
$$

From the equilibrium strategies, it is straightforward to determine how changes in the relative gains of the contenders for winning the contest influence the probabilities of winning the contest:

$$
\begin{gathered}
\frac{\partial p^{C}}{\partial N^{H}}=\frac{N^{C}}{\left(N^{H}+N^{C}\right)^{2}}<0 \text { and } \frac{\partial p^{C}}{\partial N^{C}}=\frac{N^{H}}{\left(N^{H}+N^{C}\right)^{2}}>0 \\
\text { and } \frac{\partial p^{H}}{\partial N^{H}}>0 \text { and } \frac{\partial p^{H}}{\partial N^{H}}>0 .
\end{gathered}
$$

Note that $N_{\alpha}^{H}>0, N_{\beta}^{H}>0, N_{\beta}^{C}>0$ and $N_{\alpha}^{C}>0{ }^{17}$. E.g., look at $N_{\beta}^{C}$. Since a larger $\beta$ implies demanding a larger stock by reducing harvest, for a fixed preferred harvest level of the harvester, the implication is that the larger the $\beta$ level the larger the net gain from winning the contest for the conservationalists, implying $N_{\beta}^{H}>0$. The benefit from winning is unaffected, but the benefit from losing is now smaller for the harvester.

\section{The effect of extreme position on the probability of conserving the resource}

One of the main research questions this paper is set out to address is the consequence more extreme positioned harvesters or conservationalists has on the likelihood of wining the contest.

It follows from the definition of $P^{C}$ that:

$$
\begin{aligned}
& P_{\tau}^{C}=\frac{N_{\tau}^{C}\left(N^{C}+N^{H}\right)-N^{C}\left(N_{\tau}^{C}+N_{\tau}^{H}\right)}{\left(N^{C}+N^{H}\right)^{2}}= \\
&=\frac{N_{\tau}^{C} N^{H}-N_{\tau}^{H} N^{C}}{\left(N^{C}+N^{H}\right)^{2}}, \quad \tau=\{\alpha, \beta\}
\end{aligned}
$$

Therefore, $\quad \operatorname{sign}\left\{P_{\tau}^{C}\right\}=\operatorname{sign}\left\{N_{\tau}^{C} N^{H}-N_{\tau}^{H} N^{C}\right\}=$ $\operatorname{sign}\left\{\frac{N_{\tau}^{C}}{N^{C}}-\frac{N_{\tau}^{H}}{N^{H}}\right\}$. Thereby, $P_{\tau}^{C}>0$ if $\frac{N_{\tau}^{C}}{N^{C}}>\frac{N_{\tau}^{H}}{N^{H}}$. This directly leads to the first result:

Result 1. Changes in $\alpha$ and $\beta$ affect the probability of conserving the resource as follows:

a) $P_{\beta}^{C}>0$ if $\frac{N_{\beta}^{C}}{N^{C}}>\frac{N_{\beta}^{H}}{N^{H}}$,b) $P_{\beta}^{C}<0$ if $\frac{N_{\beta}^{C}}{N^{C}}<\frac{N_{\beta}^{H}}{N^{H}}$,

$$
\begin{aligned}
& { }^{17} N_{\alpha}^{H}=\pi_{H} h_{\alpha}^{\alpha}+\pi_{\alpha}-\left[\pi_{H} h_{\alpha}^{\beta}+\pi_{\alpha}\right]=\pi_{H} h_{\alpha}^{\alpha}>0, N_{\beta}^{H}=\pi_{H} h_{\beta}^{\alpha}- \\
& \pi_{H} h_{\beta}^{\beta}=-\pi_{H} h_{\beta}^{\beta}>0, \\
& N_{\beta}^{C}=u_{S} S_{\beta}^{\beta}+u_{S}-\left[u_{S} h_{\beta}^{\alpha}+u_{S}\right]=u_{S} S_{\beta}^{\beta}>0, N_{\alpha}^{C}=u_{S} S_{\alpha}^{\beta}-u_{S} S_{\alpha}^{\alpha}= \\
& -u_{S} S_{\alpha}^{\alpha}>0, \text { Here, } S_{\beta}^{\alpha}=h_{\alpha}^{\beta}=0 \text { is used. }
\end{aligned}
$$

b) $P_{\alpha}^{C}>0$ if $\frac{N_{\alpha}^{C}}{N^{C}}>\frac{N_{\alpha}^{H}}{N^{H}}$, d) $P_{\alpha}^{C}<0$ if $\frac{N_{\alpha}^{C}}{N^{C}}<\frac{N_{\alpha}^{H}}{N^{H}}$.

The interpretation of the result is that an increase in either $\alpha$ and $\beta$ will increase the probability that the resource will be conserved, if (and only if) this change implies a larger percentage increase in the net benefit from wining the contest to the conservationalists than to the harvester. Stated differently, the group that has the highest advantage of a more extreme position also has a larger probability of winning the contest.

One interesting implication of this result is a situation where a conservation group moves in a more aggressive position. Moreover, considering the case where the harvesters experience large losses from not winning the contest. As a consequence, the conservation demands a larger conservation effort, implying larger reduction in current harvest level, this may result in a smaller probability that the resource actually will be conserved ${ }^{18}$.

This may imply a large cost to fishermen if they lose e.g., closing their businesses - and consequently, they will invest large resource in lobbying to win the contest.

How will the introduction of worsening environmental conditions affect the result from section 3? In order to analyze this, let us introduce an environmental index, $I \geq 0$ where $I=0$ defines the initial environmental conditions, while $I>0$ implies a worsening environmental condition in the following sense: $S_{H I}<0$. This implies that under worsening of environmental conditions, a unit more harvest reduces the stock more. The idea is that when $I$ increases, for a given harvesting rule, the resulting stock will be reduced. On the other hand, we let $S_{I}=0$, such that the effect of worsening environmental conditions only works through harvest decision and not directly through the stock.

How will worsening of environmental conditions affect the probability of conservation? Here the result on conserving the resource can be derived as:

$$
\begin{aligned}
P_{I}^{C} & =\frac{N_{I}^{C} N^{H}-N_{I}^{H} N^{C}}{\left(N^{C}+N^{H}\right)^{2}} \\
\operatorname{sign}\left\{P_{I}^{C}\right\} & =\operatorname{sign}\left\{N_{I}^{C} N^{H}-N_{I}^{H} N^{C}\right\}
\end{aligned}
$$

Result 2. The worsening of environmental conditions leads to a smaller probability of conservation, if:

\footnotetext{
${ }^{18}$ As an example, in 2006, WWF demanded the full closure of the cod fisheries in Baltic Sea: "A necessary step to recovery is a closure of the cod fishery in the eastern Baltic until the stock can be documented as being outside the high risk zone and has entered the overfishing square" quote page 18 (WWF, 2006).
} 


$$
\frac{N_{I}^{C}}{N^{C}}<\frac{N_{I}^{H}}{N^{H}} .
$$

This result seems striking in the sense that when the stock is under more stress that it cannot be guaranteed that it is more likely that the stock gets conserved.

To go one step deeper into this result, note that:

$$
\begin{aligned}
& N_{I}^{C}=u_{S}\left(S_{I}^{\beta}-S_{I}^{\alpha}\right), \\
& N_{I}^{H}=\pi_{h}\left(h_{I}^{\alpha}-h_{I}^{\beta}\right) .
\end{aligned}
$$

Result 2 can be re-written as: $P_{I}^{C}<0$ if $\frac{u_{S}\left(S_{I}^{\beta}-S_{I}^{\alpha}\right)}{N^{C}}<$ $\frac{\pi_{h}\left(h_{I}^{\alpha}-h_{I}^{\beta}\right)}{N^{H}}$. Hence, it is more likely that $P_{I}^{C}<0$ the larger $\pi_{h}$ compared to $u_{S}$, which implies that the harvesters profit is more sensitive to changes in harvest than the conservationalists' utility with respect to changes in the stock. This could be the case when, e.g., fishers are very dependent on the income from fishery. In such a situation, fishermen will have a large loss if they do not win the contest, since now the implied harvest level is reduced due to worsening environmental conditions. They will therefore invest more in winning the contest, and making it less likely that the resource is conserved.

Look at an example, and consider that $\alpha=1$ (or close to 1 ). In this case, $h_{I}^{\alpha}=0$, as the harvesters do not all all care about the future when $\alpha=1$.

Moreover, for any $\beta$, it also follows that $S_{I}^{\beta}=0$, since the choice of $S$ is unaffected by changes in $I$. Therefore:

$$
\begin{aligned}
& N_{I}^{C}=u_{S}\left(S_{I}^{\beta}-S_{I}^{\alpha}\right)=-u_{S} S_{I}^{\alpha}>0 \\
& N_{I}^{H}=\pi_{h}\left(h_{I}^{\alpha}-h_{I}^{\beta}\right)=-\pi_{h} h_{I}^{\beta}>0
\end{aligned}
$$

Note first that $h_{I}^{\beta}$ and $S_{I}^{\alpha}$ are somehow correlated, since $h_{I}^{\beta}$ measures the reduction in harvest for a given $S$ when $I$ goes up, while $S_{I}^{\alpha}$ measures the reduction in stock for given harvest as $I$ increases.

Now consider that profits are low (e.g., due to open access for a long time), and the harvesters are now being in a financial downturn. If they lose the contest, some or all of them might very well go bankrupt. Therefore, $\pi_{h}$ is large and the net gain from wining large. This would imply that the harvesters will willing to invest much to win and consequence, the probability of conservation the resource will smaller (potentially ending in a situation where both the fishery and the stock will collapse).
This is, however, not the full story. It the stock is decreasing, and potentially to a critical level (where recovery is problematic, and or collapse is a possibility), $u_{S}$ also tends to be high and the net benefit from winning the contest also is large for the conservationalist. This has then an offsetting effect on the probability that the stock will not be conserved due to the increased pressure from the harvesters.

From a policy point of view, and given the political contest model, a way to increase the likelihood of conservation in this particular case will be to support harvester, such that in case of losing the contest, the cost of losing not so severe. This could be policies as providing fishers with outside options or even subsidies. These normally doomed inefficient measures, but in this case, they help conserve the stock by reducing the loss for the fishermen from not winning the contest, and thereby reducing their lobby effort.

One way of introducing asymmetry into the model is by introducing a cost parameter $\gamma>1$. Now the welfare functions for the two contenders are given by:

$$
\begin{aligned}
E\left[W^{H}(\alpha, \beta)\right]= & P^{H} \cdot \pi\left(h^{\alpha}, \alpha\right)+P^{C} \cdot \pi\left(h^{\beta}, \alpha\right)-\gamma \\
& \cdot x^{H} \\
E\left[W^{C}(\alpha, \beta)\right]= & P^{C} \cdot u\left(S^{\beta}, \beta\right)+P^{H} \cdot u\left(S^{\alpha}, \beta\right)-x^{C}
\end{aligned}
$$

From this, it is possible to derive the new equilibrium contribution levels as:

$$
x^{C}=\frac{N^{H} \cdot \gamma \cdot\left(N^{C}\right)^{2}}{\left(N^{H}+\gamma \cdot N^{C}\right)^{2}}, \quad x^{H}=\frac{N^{C}\left(N^{H}\right)^{2}}{\left(N^{H}+\gamma \cdot N^{C}\right)^{2}} .
$$

Inserting these into the expression of $P^{C}$ yields the probability of conservation in equilibrium as a function of $\gamma$ :

$$
P^{C}=\frac{x^{C}}{x^{H}+x^{C}}=\frac{\gamma \cdot N^{C}}{\gamma \cdot N^{C}+N^{H}}
$$

Now, it is possible to derive how the cost parameter affects the probability of conservation:

$$
\begin{gathered}
P_{\gamma}^{C}=\frac{N^{C}\left(\gamma \cdot N^{C}+N^{H}\right)-N^{C} \gamma \cdot N^{C}}{\left(\gamma \cdot N^{C}+N^{H}\right)^{2}}= \\
=\frac{N^{H}}{\left(\gamma \cdot N^{C}+N^{H}\right)^{2}}>0
\end{gathered}
$$

As long as $\gamma>1$, it makes sense that $P_{\gamma}^{C}>0$. The interpretation of an increase in $\gamma$ in this contest could be that conservation issues achieve more support, either from more focus from the public and/or more support in the political area, moving up the conservation issue in the political arena. As a 
consequence, it is becoming continuously more difficult for the harvester to influence the decision makers. More precisely, it is becoming more costly for the harvesters to influence the probability of wining the contest. Therefore, by the logic of the contest model, the harvester will invest less into the contest. This can be seen from the expressions of $x^{H}$ and $x^{C}$, where it follows that $\frac{x^{C}}{x^{H}}$ increases with increasing $\gamma$.

\section{Discussion and conclusion}

All results in this paper are based on the simple, but strong logic of the political contest model that the group that has the relatively largest increase in the net benefit from wining the contest also will increase its probability of wining the contest. Even without specifying any lobby technology, by which lobby effort translates into policy influence, many authors argue that the policy contest model summarizes a fundamental driver of lobbying and its effect on the policy outcome. The more is at stake for the lobby group the more will this group invest into the policy process to gain policy advantages. Therefore, whether a more extreme conservation or more extreme harvesting group wins the contest depends on the relative change in net benefit.

The analysis is based on a number of assumptions. It is therefore appropriate to discuss their justification.

The analysis has exclusively focused on the probability of conservation or the resource. Note that, e.g., in the case where a more extreme conservation group implies a smaller probability of conservation, the expected (ex ante) stock could very well be larger. The reason being that we less often see the resource being conserved, but when it does, then the conservation is more extensive since the expected size of the stock then depends on the change in the size of the conservation and of the probability of conservation. However, restricting attention to $P^{C}$, still is important for a number of reasons. If, e.g., the resource is under pressure (in particular if a harvest group with large $\alpha$ is the opponent), then losing the contest can imply a collapse of the resource, and in this case, a more extreme conservation group might therefore increase the probability of a collapse of the resource (given the condition from result 1a).

Often policies (like the catch level for a given fishery) are found to be on a continuous line (even though some focal points can be identified). In our setting, there are only two possible outcomes (for a given $\alpha$ and $\beta$ ). However, the way the positions are defined, any harvest rule from an open access to a zero harvest is feasible. Therefore, ex post, any harvest level is possible. It is also possible to consider variations in the outcome of the political process for given for a given $\alpha$ and $\beta$. After all, there are other factors that influence the political decision than lobby effort. In this case, the "chosen policy", e.g., could be drawn from a pdf with mean equal to the position of the winner.

Throughout $\alpha$ and $\beta$ are treated endogenous, even though we analyzed changes the position of the contenders. For the conservation group, the position could very well be defined by some kind of aggregation over member preferences. Preferences might change either by inflows and outflows of members, and also, e.g., by changes in knowledge, awareness, and social factors. For the harvesters, the position to a large degree is determined by the discount factor hold by the group. A more extreme position of harvesters could occur if the economic conditions of the harvesters deteriorate, making the need for more short-sided decisions more pervasive. Note, given condition c) of result 1 is met, the probability of wining the contest might then be even less for the harvester. (Even though the expected harvest might be larger, the probability of, e.g., going bankrupt will increase).

Finally, what happens if conservation is not successful? E.g., an interesting aspect here is that from the identification of an environmental or resource problem until regulation is in place and until the problem is resolve take many years or even decades (see Varjopuro et al., 2014). In this case, there are several possibilities. But in this model the implication is simple; the net benefit of the conservation group from wining will be lower, while the net benefit from winning remains unaltered, so the probability of conservation will fall.

\section{References}

1. Brandt, U. S., \& Svendsen, G. T. (2016). The Politics of Persuasion: Should Lobbying be Regulated in the EU? Edward Elgar Publishing.

2. Brandt, U. S., \& Svendsen, G. T. (2009). Trawling for subsidies: the alignment of incentives between fishermen and marine biologists. Journal of European Public Policy, 16, 1012-1029.

3. Dijkstra, B. R. (1998). Cooperation by way of support in a Rent Seeking Contest for a Public Good. European Journal of Political Economy, 14, 703-725. 
4. Eerola, E. (2004). Forest conservation - too much or too little? A political economy model. Environmental and Resource Economics, 27, 391-407.

5. Epstein, G. S., \& Nitzan, S. (2002). Stakes and Welfare in Rent-Seeking Contests. Public Choice, 112, $137-142$.

6. Epstein, G. S., \& Nitzan, S. (2007). Endogenous policy and contests. Berlin: Springer.

7. Epstein, G. S., Nitzan, S., \& Schwarz, M. E. (2008). Efforts in two-sided contests. Public Choice, 136, $283-291$.

8. EU (2005). European Commision: Thematic Strategy on the Protection and Conservation of the Marine Environment. European Commission, Brussels, Belgium.

9. EU (2008). The Marine Strategy Framework Directive. (MSFD 2008/56/EC, EC 2008).

10. Graichen, P. R., Requate, T., \& Dijkstra, B. R. (2001). How to Win the Political Contest: A Monopolist vs. Environmentalists. Public Choice, 108, 273-293.

11. Hovi, J., Underdahl, A., \& Ward, H. (2011). Potential contribution s of political science to environmental economics. Environmental and Resource Economics, 48, 391-411.

12. ICES (2005). ICES. Retrieved from http://www.ices.dk/marineworld/recoveryplans.asp

13. IPCC (2014). Fifth Assessment Report, synthesis report. Retrieved from www.ipcc.ch/

14. Juda, L. (2010). The European Union and the Marine Strategy Framework Directive: Continuing the Development of European Ocean Use Management. Ocean Development \& International Law, 41, 34-54.

15. Liston-Heyes, C. (2001). Setting the Stakes in Environmental Contests. Journal of Environmental Economics and Management, 41, 1-12.

16. Long, R. (2011). The Marine Strategy Framework Directive: A New European Approach to the Regulation of the Marine Environment, Marine Natural Resources and Marine Ecological Services. Journal of Energy \& Natural Resources Law, 29, 1-44.

17. Ludwig, D., Hilborn, R., \& Walters, C. (1993). Uncertainty, resource exploitation and conservation: Lessons from history. Science, 260, 36-37.

18. Nitzan, S. (1994). Modeling Rent Seeking Contests. European Journal of Political Economy, 10, 41-60.

19. Olson, M. (1965). The Logic of Collective Action. Cambridge University Press, Cambridge.

20. Pauly, D. (1995). Anecdotes and the shifting baseline syndrome of fisheries. Trends in Ecology and Evolution, 10, 430.

21. Richards, J. P., \& Heard, J. (2005). European environmental NGOs: Issues, Resources and Strategies in the Marine Campaigns. Environmental Politics, 14, 23-41.

22. Varjopuro, R., Andrulewicz, E., Blenckner, T., Dolch, T., Heiskanen, A.-S., Pihlajamäki, M., Brandt, U. S., Valman, M. , Gee, K., Potts, T., \& Psuty, I. (2014). Coping with persistent environmental problems - Systemic delays in reducing eutrophication of the Baltic Sea. Ecology and Society, 19, 48.

23. Wilen, J. E. (2000). Renewable Resource Economists and Policy: What Differences Have We Made? Journal of Environmental and Economics and Management, 39, 306-327.

24. WWF (2006). A Sustainable Future for Baltic Sea Cod and Cod Fisheries. WWF Baltic Ecoregion program, WWF, Denmark. 